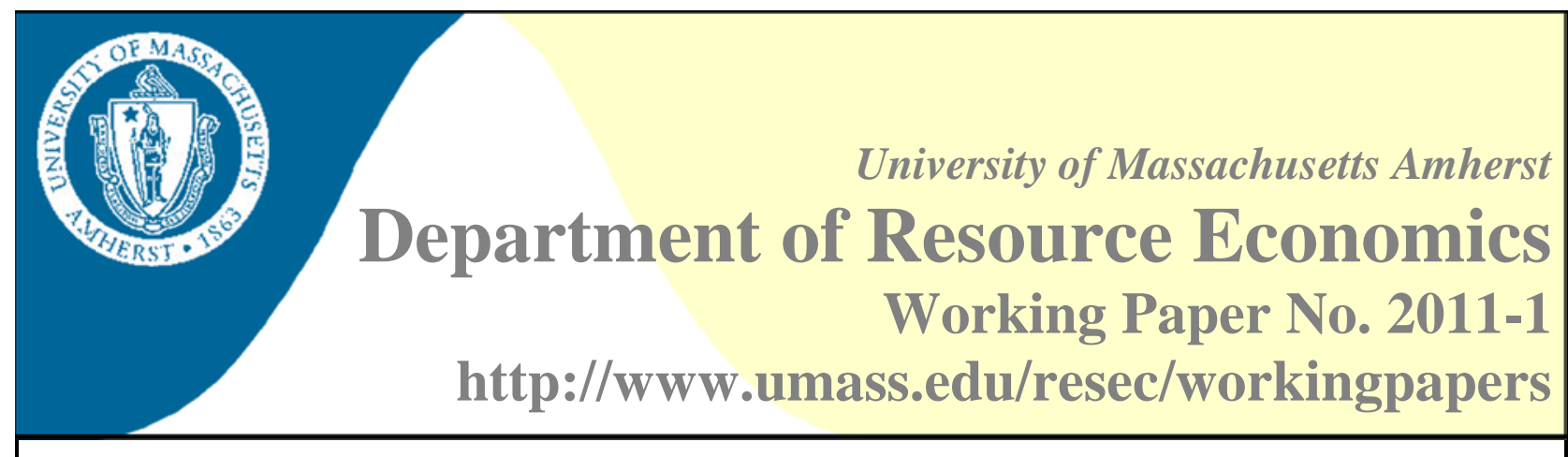

\title{
Think Before You Tweet: Social Media Best Practices for Undergraduate Business Schools Donna I. M. Spraggon ${ }^{1}$
}

\begin{abstract}
:
There are more than 100 social media tools available to higher education institutions to reach potential, current and past students. Both students and institutions are making use of social media, however, the latter are typically not taking full advantage of what is available. In this paper, I explore best practices in social media as they pertain to undergraduate business schools. An examination of 20 business schools reveals a large disconnect between social media best practice theory and those practices observed. Building on the identified best practices, I have constructed a suggested model for social media for a business school undergraduate program aimed at recruitment, retention and alumni investment.
\end{abstract}

Keywords: advising, business school, recruitment, retention, social media

JEL Classification: M00, A20

\footnotetext{
${ }^{1}$ Donna I. M. Spraggon, Department of Resource Economics University of Massachusetts, 208C Stockbridge Hall 80 Campus Center Way, Amherst, MA 01003-9246

E: dspraggo@resecon.umass.edu P: 413-545-5712 F: 413-545-5853
} 
March, 2011

Think Before You Tweet: Social Media Best Practices for Undergraduate Business Schools

\author{
Donna I.M. Spraggon \\ Department of Resource Economics \\ Isenberg School of Management \\ University of Massachusetts Amherst
}

\begin{abstract}
There are more than 100 social media tools available to higher education institutions to reach potential, current and past students. Both students and institutions are making use of social media, however, the latter are typically not taking full advantage of what is available. In this paper, I explore best practices in social media as they pertain to undergraduate business schools. An examination of 20 business schools reveals a large disconnect between social media best practice theory and those practices observed. Building on the identified best practices, I have constructed a suggested model for social media for a business school undergraduate program aimed at recruitment, retention and alumni investment.
\end{abstract}

Keywords: advising, business school, Facebook, recruitment, retention, social media.

Correspondence: Donna I. M. Spraggon, Department of Resource Economics, 208C Stockbridge Hall, 80 Campus Center Way, University of Massachusetts-Amherst, Amherst, MA 01003, USA. Phone: (413) 5455712, Fax: (413) 545-5853, E-mail: dspraggo@resecon.umass.edu.

Acknowledgement: I am greatly appreciative of the valuable input I received from Julie Caswell, Kim Figueroa, Anne Fortier, Alex Niefer and John Spraggon. The impetus and generous support for this paper was provided by Carol Barr and the Isenberg Undergraduate Program Office. 


\section{Think Before You Tweet: Social Media Best Practices for Undergraduate Business Schools}

\section{Introduction}

The newness of social media means there is a considerable lack of in-depth research and development of best practices concerning its use as a communication tool with undergraduate students. A UMassDartmouth Center for Marketing Research study uncovered that, in general, social media was employed at a faster rate by higher education institutions than by Fortune 500 companies (Ganim Barnes, 2010). However, institutions of higher education are typically not taking full advantage of the opportunities presented by social media, especially considering that there are more than 100 social media tools available. For example, higher education institutions' Facebook pages are strikingly similar and make minimal use of features available (McDonald, 2009). Although Facebook was designed for college networking and later expanded to the public and companies, it is most incredible that the Facebook presence by a higher education institution may have very few "Friends" or those indicating they "Like" (McDonald, 2009).

The research for this report focuses on four main avenues. The first is the initial focus of the project: to examine other business schools for best practices in social media. This resulted in an in depth examination of 20 undergraduate business schools' websites and social media endeavors. These particular schools were considered of interest due to at least one of the following factors: reputation, geographical location or school type (public/private). Secondly, searches of literature databases revealed some publications in the areas of business, education, advising, and information technology. Thirdly, an internet search revealed social media marketing best practices, by far the most prominently discussed area of best practices relating to social media. Finally, discussions with members of my institution's business school's Alumni Office, Career Center, and Undergraduate Program Office put the resulting best practices in context. 
Through this extensive search, limited best practice research was found relating to social media. Furthermore, examination of the 20 business schools identified a disappointing number of best practices. There appears to be a large disconnect between social media marketing best practice theory and those practices observed in higher education in general and in business schools in particular.

The following explores identified best and worst practices from social media marketing, higher education, and advising. Discussion of the business school observations supports the necessity of following such best practices. Throughout, one overarching best practice prevails: developing a social media strategy prior to embarking on any social media endeavor. This framework will serve as the base for a suggested model for a social media for a Business School's Undergraduate Program Office.

\section{Best Practices}

Ganim Barnes and Mattson (2010) at the UMass-Dartmouth Center for Marketing Research have now completed a 3-year longitudinal study concluding that higher education institutions are adopting social media tactics such as social networking sites and blogging at a faster rate than Fortune 500 companies. While higher education institutions are quicker to employ social media tactics, it may be that companies are favoring a more methodical approach. This overarching best practice of taking time to build a strategy allows targeting and more easily engages the audience in a meaningful way than the "build it and they will come" approach to social media. An example of the strategic approach is:

Framework for Social Media Strategy (Odden 2008, 2009)

\section{Audience}

Knowing the audience and how they interact in the various available social media tools will quickly determine how invested an undergraduate programs office wishes to be. Although many undergraduate students may use various social networks, their reasons for using them may be beyond the scope of an undergraduate programs office and hence be a wasted investment. 


\section{Objectives}

Because social media are actually based on interaction, exchange of information, and "giving to get", the objectives of the organization really need to meet the objectives of the audience that is being sought. To some extent they are mutual objectives on the surface. However, the organization and audience are likely to have different reasoning behind the objectives. Being aware and responsive to the audience's goals ensures the creation of a vested community.

3. Strategic Plan

What approach can be taken to satisfy the intended audiences' needs and in the end meet the needs of the organization?

4. Tactics

How to implement the plan? What type of social media tool (blogging, microblogging, social networking sites, video, forums, etc.) to employ and when? Will content be separate or replicated between: social media tools, social media tools and main website, and social media tools and in-person services? There are a considerable number of types or categories of social media tools available and within each category, many tools are being commonly used. It is easy to get overwhelmed and have a tendency to over diversify the social media effort. Some higher education web communication initiatives are experiencing the cost of overinvestment and restricting their concentration to one or two tools (Lipka, 2009). Still other institutions are deciding to wait and consult with their students to see how it plays out.

5. Tools

What specific tools will be used? There are over 100 social media tools in existence. Of primary concern to an organization would be whether they wish to offer a one- or two- 
directional communication link to its intended audience (boyd, 2008). If looking to build a community and develop long-term investment in the organization then tools offering twodirectional communication are best suited.

\section{Metrics}

How will success be measured in light of the objectives? Which measurement tools to employ and when? Are there results to share with different stakeholders? Furthermore, should these success metrics be shared with the audience?

Social media may be public relations more than direct marketing. Resources A result in action B that influences outcome C. Measurement of success is often not direct. Pre-goal indicators such as number of "friends", comments, links, etc. combined with live participatory indicators (survey results, timeline compliance, recruitment, etc.) that are influenced by social media will better show social media success.

Other considerations in building a social media strategy:

- Resource and time commitment

Implementing the social media strategy is not a one-time cost. Continual management, monitoring, and progression are necessary to keep the undergraduate programs office plan current. Odden (2009) suggests that you plan as if the strategy is successful rather than underestimate the consequences and drain on resources that the foray into social media may cost.

The initial setup cost of creating a social media endeavor is wasted "unless you have the dedicated time and resources to maintain new content on a regular basis" (Colorado State University n.d.). Colorado State University Best Practices suggest new content generation on a weekly basis. 
- Transparency about intentions (Odden 2009)

State purpose and keep it focused on increasing the value of the tool for the user.

- Building community: Encourage participation, feedback, and co-creation

No censorship

Removal of comments that are not threatening or obscene can cause more harm than good as experienced by Ohio State University when "the university removed from its Facebook page comments about the president's relationship with an energy company criticized by environmentalists" (Lipka, 2009, p. A4).

The message is not controlled or managed in social media In fact, McLuhan's thesis (1964), "The Medium is the Message" applies since the major message is the social media tool itself. The exchange taking place is fluid and most often two-way. With that comes certain risk. However, any attempts to mitigate that risk will only stifle participation and destroy fostering of the community.

Facilitate buy-in

Sheridan (2009) contends "People trust people, not institutions." This is further supported by the 2006 Edelman Trust Barometer finding “Person Like Me is Most Credible Spokesperson" (http://www.edelman.com/trust, Retrieved August 1, 2010). The more people who are active in the community the more people will trust and communicate, and the more the institution gains. This suggests the use of student facilitators (developers) to enhance buy-in.

\section{Respond quickly}

Assign accountability and create vested interest in keeping social media efforts current (De, 2009). The State University of New York at New Paltz has staff members committed to posting answers on the college's Facebook page within two hours (Lipka, 2009). 
Bring it full circle

De (2009) stresses the importance of a strong visual identity online that is consistent with the brand identity. If the audience needs to spend an inordinate amount of time looking for the brand online, they will stop looking. Common practice is to place social media widgets on an organizations' main website but equally important is to bring the social media users back from the social media experience to the content rich website. Each forum has different information carrying abilities and intentions; information available on the website may not be available on the social media site and vice versa. Finally, in most cases, social media is used to reinforce or strengthen "pre-existing social relations" (boyd, 2008, p. 221).

- $\quad$ Content matters most (McDonald, 2009)

User-generated content elicits participation

Deciding on the balance of institutional- versus user-generated content during the planning stage will assist in establishing realistic expectations for success. Further to this balance, the volume of updates in social media also matters. In the same way that students have ceased to pay attention to e-mails originated from the higher education institution system, too much volume on a social media tool could cause student to disengage (Advising, 2010).

\section{Empower your users}

Entering into a social media tactic does not create a community. Empowering users/audiences to communicate their stories which collectively represent the brand's (institution's) story fosters a community. Ultimately, "strong brands will come from strong dialogue" (McDonald, 2009, p. 46). More specifically related to higher education institutions and advising capacity, social media does not represent the university entity to most students (Advising, 2010). In fact, most students were likely engaged in some form of social media before they joined the university. Higher education institutions are now trying to engage students outside the traditional brick and 
mortar. Giving students the freedom to choose whether they participate and to what degree is in keeping with the design of social media where the user controls the content and the interactions. Meanwhile, you further empower the user as you provide resources for answering their questions (Ray, 2007), where the gain some satisfaction in seeking and finding the solution.

\section{Guidelines and policy}

Setting expectations via policy and guidelines for the users of social media when representing a higher education institution or its schools, departments, etc. is imperative to protecting branding and the various stakeholders' rights and interests. Roughly one-third of higher education institutions have established policy and guidelines for the use of social media as it relates to the institution (Ganim Barnes, 2010). Some institutions, such as Colorado State University (CSU) (n.d.) and Cornell University (Mitrano, 2006), in addition to policy and guidelines provide educative pieces to assist users in being more informed about the social media they are employing and the effects of their decisions.

\section{Disclaimer}

Once a social media policy has been established, the additional dissemination of a social media disclaimer will provide clarity as to ownership and responsibility of content and discretion. This should be placed on the chosen tool created site for every site associated with the school. Caution also must be taken to not violate free speech when considering the removal of usergenerated postings (Lipka, 2008).

\section{Worst Practices}

The following were identified as worst practices in social media by Odden (2009).

- Being misleading in any way

By misleading the audience in social media, even in the slightest, the communication line will be altered and the achievement of mutual goals and objectives compromised. It is important to not 
overstate the importance or significance of participation in the community as any disappointments will be publicly aired.

- Not listening Listening is the most important step in communication. Active listening in social media allows for learning about, encouraging, and supporting the community that you are hoping to foster. The ongoing monitoring of dialogue and attitudes, when appropriately responded to (be it by posting or action) will strengthen both the online and physical community being served. Individuals will also be identified and recognized as influential in the community.

- Ignoring formal and unwritten social rules

All social media sites have Terms of Service. However, a community will have unwritten rules or guidelines for behavior. Most are obvious, like avoiding inappropriate content, while some may be less so. For instance, undergraduate Facebook groups seemed to have more dialogue when less formal (pointed) postings were made by the administrators regarding undergraduate affairs.

- Being pushy or overtly "salesy" in messaging Social media is not standard communication. Individuals participate because they have control and are able to guide and build the community in which they choose to participate. One goal is to make a social media community welcoming in hopes that participants will be attracted to the real-world community being offered. Constant directed messaging ("salesy") interrupts the conversation. Putting the same message content into similar language of the dialogue flow of the community will serve to buffer the resistance while getting the point across.

- Approaching social media as silos

The silo approach to social media is inefficient for both company (school) and consumer. The coordination of efforts can reduce mixed messages and loss of followers due to improper nomenclature, coverage, etc. Laying out the extent of collaboration/coordination as part of the 
Social Media strategy within the school will reduce the inefficient silo effect. The centralization of coordination is also identified as a best practice of social media implemented by the Top 100 Brands (ENGAGEMENTdb.com, 2009).

- Staffing inappropriately

Depending on the strategy planned, social media takes a lot of time to work appropriately. Active listening and liaising with appropriate bodies within the school organization is not something that can be tacked on to another full-time schedule. The social media staff must be appropriately skilled in both the tools to be utilized and the content being articulated (such as advising matters, etc.). Research by ENGAGEMENTdb (2009) suggests a way to mitigate staffing concerns as observed in the Top 100 Brands is by spreading engagement to employees beyond the social media team. Make social media part of the job (just like email) and make it part of everyone's job. However, it is important to stay in keeping with the overlying social media strategy and keep consistent messaging and timelines. To this end, centralized management of the social media strategy is suggested.

- Not having a an appropriate mechanism to assess Return on Investment (ROI)

Either under- or over-valuing the contribution of the social media in achieving the organization's intended objectives will result in missed opportunities and wasted resources. Clearly defining the metrics that will indicate the level of objective achievement before starting the social media journey can serve to place more focus on the objectives and people and less on the tools and gadgets of social media.

\section{Business School Social Media Observations}

A total of 20 U.S. business school websites were observed as part of this survey of best practices in social media as applied to undergraduate programming in business schools. Of these, 10 were public institutions. As geographic location is important for recruitment, the schools studied were comprised of 
11 from the Northeast (six in Massachusetts), three from the Mid-Atlantic, five from the Midwest and one from the West. Seven of the schools were within the top 10 of the BusinessWeek Undergraduate Rankings for 2010, 13 of the schools were within the top 30 and 18 within the top 50. The schools' websites were studied between June $20^{\text {th }}$ and October $7^{\text {th }}, 2010$.

Of the 20 business schools observed, 12 of the school's main websites did not contain any reference (widgets, icons, links, or otherwise) to any form of social media. However, over half of the schools did have a school administrated Facebook presence. With this passive form of social media acknowledgement it is perhaps unsurprising that the highest participation rate was less than $10 \%$ of the fulltime enrollment. Also, there is a considerable range of social media usage among these schools ranging from zero to as many as ten social media tools being advertised on the main website.

Social media usage did not transfer uniformly passing from school level to programs. While the main website would reference social media tools such as Facebook, YouTube, Twitter, etc., these would not necessarily be carried to undergraduate programs. When social media was listed in the undergraduate programs area it was in relation to admissions (recruitment) and career centers. Most undergraduate programs webpages do not refer to social media endeavors unless utilizing student blogs or video. The exception was one school where the use of Facebook for new students was clearly advertised.

Even though the schools and undergraduate programs do not indicate social media usage, they can still be found on such tools as Facebook whether school initiated or not. In most cases, there is little or no consistency on these Pages or Groups with regards to naming, school/program based content, branding, maintenance, etc. There is also minimal structure to schools' Facebook presence. While many sub entities of the school, such as Alumni, Career Services, and Classes were found there was no linking and cross-referencing to indicate a non-silo approach. Only one school showed an attempt at branding consistency. 
There was no evidence to support that any of these 20 schools had approached social media in a way consistent with the best practices identified in the literature and marketing field. A school willing to put forth the effort and commitment in this endeavor would be leading the way.

\section{Suggested Model for a Business School's Undergraduate Program Social Media Anchored in a Best Practices Framework}

The following outlines a model for an undergraduate program that is anchored in the social media best practices framework constructed above. In some instances, pros and cons are weighed as the specific details necessary for the implementation of a social media program will need to be further discussed with stakeholders.

\section{Audience}

McDonald (2009) notes the most common key audiences for higher education institutions include:

- $\quad$ Prospective students and their parents

- Current students and their parents

- Prospective Faculty

- $\quad$ Current Faculty

- Current undergraduate students

- Current graduate students

- Prospective donors

- Donors and alumni

- Friends, such as business and community leaders

\section{Objectives}

RECRUIT: Recruitment

- $\quad 1$ st year students from state and out-of-state

- Off Campus Transfers 
- On Campus Transfers

- Honors

- Diversity

- Parents

RETAIN: Student Retention and Success

- Enhance points of contact

- Provide consistent and easily attained information

- Foster sense of community

- Take care of student needs

- $\quad$ Easy access to advising and mentoring

- Internship and career preparation services

REMAIN: Vested Alumni

- $\quad$ Career services

- Alumni communication

- Nurture established community

\section{Strategic Plan}

Provide an integrative approach (non-silo) to provide seamless transitioning for students from beginning to end of undergraduate careers and beyond.

By being with students from when they first think of becoming a student of that business school and throughout their success, a well-planned social media map will ensure a student's easy transitioning. They should have easy access to all facets of the Business School's social media package with no duplication or inconsistency. This will require that all units utilizing social media work together to coordinate their efforts to maximize chances of success. Effective use of links, applications, and guidelines will assist in this endeavor. 


\section{Social Media Policy/Guidelines}

The establishment of Business School-wide social media policy/guidelines to further any existing university web community or social media guideline and policy would help to fully inform and encourage the Business School's community to participate in a safe and welcoming environment. In particular, issues of acceptable and consistent branding and disclaimers should be addressed.

For example, a study of undergraduate students indicates that approximately $20 \%$ acknowledge having content on their social network profile that they would not want a potential employer to see (Peluchette, 2008). Development of guidelines and education about necessary cautions (e.g., permanency due to caching and privacy (Clark, 2010)) in social media communication is identified as a best practice (e.g. Cornell University). It can be communicated to students via traditional contact such as the first-year experience course or other key courses, as well as be addressed in social media directly. Set Social Media Operation Policy and Expectations

1. Response Time

2. Guidelines for question referral (triage system)

3. Content Guidelines

\section{Tactics}

1. Social Networking Sites (SNS)

2. Video

\section{Tools}

\section{Facebook}

\subsection{Why Facebook?}

Undergraduate students and those in high school are heavy users of Facebook. Peluchette and Karl (2007) studied over 433 undergraduate students with over half being business majors and found $80 \%$ using at least one social networking site (Facebook most popular). Over $50 \%$ indicated 
they entered their site a minimum of once per day. This is consistent with the University of Oklahoma's University College experience where students ceased reading university generated emails and claim that they are on Facebook much of the time that they are not engaged in normal undergraduate routines such as bathing, eating, attending class, studying, exercising, etc. (Ray 2007).

\subsection{Group or Page?}

Facebook Groups allow for the building of a community around discussion and information sharing on specific subjects. A Group lends itself easily to two-way discussion and content sharing such as videos and photos and is generally used by clubs, companies and the public sector to interact with stakeholders. Some features available in a Group include: "friends", discussion board, wall content, photos, videos, posted items, and a news feed.

Facebook Pages on the other hand, allow owners to create profiles that users may indicate that they "Like". From an owner's perspective, Page benefits include: easy (but not free) setup in the Facebook advertising system, ability to send updates to their fans, and availability of analytical packages for market analysis of Page usage. Additional customization of the Page for specialized content, in the form of new Tabs, can also take place.

\subsection{Ability to utilize Facebook within various advising frameworks}

Advising methods encouraging students to actively engage in their advising and education outcomes are well suited to social media tools such as Facebook. For instance, the Appreciative Advising framework lends itself easily to Facebook or other social media endeavors (Pou, 2010). This social constructivist advising theory optimizes adviser-student interactions by breaking down possible barriers and facilitating the co-creation of a plan for success that empowers the students to eventually deliver on their plan. Facebook interaction can break down barriers if the participants (advisers and students) are willing to divulge. Co-creation is facilitated by the many tools available. 
Although advising works best in a one-on-one situation, today's technologically literate students may be more likely to engage in advising in a forum such as Facebook if it minimizes the effort they need to put in (such as attending the advising office).

\subsection{Will Facebook become the new E-mail?}

Facebook has been employed successfully as an advising tool as it can alleviate time-consuming duplicate e-mail. It can effectively reach students who have disengaged from e-mail (Ray 2007; Traxler 2007), as well as providing the opportunity for advisers to stay engaged with the student body and remain relevant to their experience (Esposito, 2007). However, in answer to users' complaints, the most recent version of Facebook gives users the ability to easily select the amount they hear from certain friends, groups, and like pages (Facebook). Given this ability, it is possible for a student to "turn off" the feed from a "Friend" or "Like" and then only see update if they visit the Group or Page.

1.5. Encourage sharing of the Business School experience with competitions for sharing videos, photos, and feedback

Videos, photos, comments, etc. can be posted on Facebook to share with the community.

\section{Embedded video - possibly YouTube content}

\subsection{Why YouTube?}

Popularity and ability to integrate with Facebook and websites.

Subject possibilities: Academic planning, Important Dates and Deadlines, Information about departments/majors/etc., Perspectives from advisors, Student perspectives, Faculty interviews, Outside classroom opportunities, Parent perspectives.

Benefits: Enhance active student learning through engagement, sense of community, connection fostering, and extension of the undergraduate programs office beyond the brick and mortar.

Cost: Video planning, development and production. 


\section{Metrics}

Acceptable metrics would need to be set before implementation of a social media endeavor.

Possibilities include percentage of undergraduate student participation, advising office log book counts across social media content postings, recruitment capture, and senior survey.

\section{Suggested Facebook Structure}

The Facebook structure outline in Figure 1 is intended as a base framework from which to build the intricacies of the Business School's social media strategy. Particular attention is paid to the role of undergraduate programming. This structure emphasizes the need for links between units to promote seamless transitioning for students, retention, and alumni engagement.

\subsection{Overall structure - Creation of sensible links}

The most significant detail of the suggested Facebook structure is anchored in the best practice of the avoidance of silo behavior. By creating links between various programs within the Business School, the audience is easily able to navigate within the Business School community without needing to search for areas of interest. Every time the audience disengages from the content of the Page or Group to search is a risk that they become dissatisfied with service provided. By making sensible linkages available within the Facebook structure, a user stays engaged in the Business School and in the content and their overall satisfaction with service provided may increase.

A further reason to provide sensible links between Pages and Groups within the Business School Facebook structure is to maximize the efficiency of content development and the audiences' exposure to content. For instance, Career Services provides a wealth of information to undergraduate students throughout their years at the Business School. By having the opportunity to link that information to the appropriate undergraduate Class of Year Group, Career Services will effectively target their intended audience as well as potentially decrease the effort needed in communication. Similar benefits can be seen for providing sensible linkages between the Departments' Pages and Groups and the Class of Year 
Groups. Ultimately, the goal is to provide the information to the audience when they are ready to seek it without overwhelming them. These sensible linkages will assist the undergraduate as they proceed through the Business School and as they proceed to graduation the number of linkages will increase.

\subsection{Page versus Group}

The extent of two-directional engagement that each program within the Business School's Facebook structure can maintain will ultimately decide whether a Page or Group will be employed. In interest of time commitment, operating the School and Programs as a Page will ease some of the maintenance costs. Some of the Program areas, such as the Career Services and the Departments may want to establish sub-areas of their program as Groups to aid in community building. Further structure can be built into this framework to aid in this process.

All Class of Year and Undergraduate Advising Facebook presence should be established as a Group. This will allow students to easily post content and encourages students/audience to communicate in a meaningful way. Also, for the purposes for advising, a Group structure (more two-directional) is similar to virtual group meetings and beneficial for the sharing of questions and answers.

\subsection{Administration}

All Facebook presence should have staff and/or faculty associated with it in an administrative and creative capacity. The Class of Year Groups however should also employ class representatives in an administrative and creative capacity. Similarly, any Programs using student ambassadors may want to engage them in social media efforts as well. Engaging undergraduate students is best done by fellow undergraduate students. By encouraging their creativity, social media student ambassadors will be able to foster the community. Furthermore, actively engaging these social media student ambassadors throughout their academic stay at the Business School may increase the likelihood that they will become Alumni representatives after graduation.

\subsection{Lifetime - Recruit, Retain, Remain...}


In order to meet the objectives of Recruit, Retain and Remain at the Business School, the Undergraduate Program Facebook structure must reflect this development and growth cycle. To this end, establishing the Business School's Class of Year Groups will allow prospective students to engage in the Business School community before they join in their first semester and then grow as a community through to graduation and beyond. As these communities develop through their own personal experiences within the Business School, the use of sensible links and rich content will assist in smoothly transitioning them from one stage of their academic experience to another. 


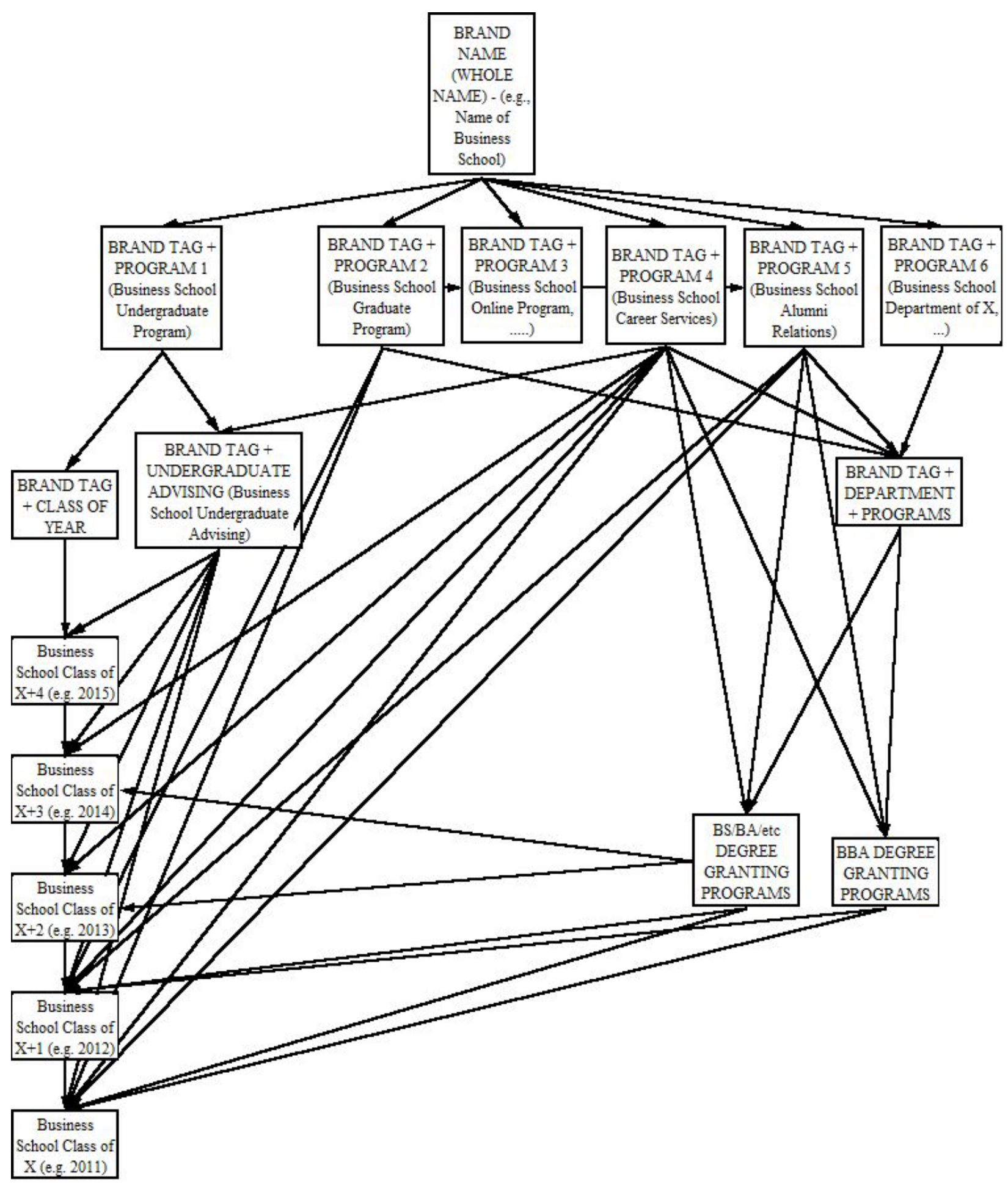

Figure 1: Suggested Facebook structure 


\section{References}

Advising, NACADA Tech in. (2010). Recommendations for Use of Online Social Communications in

Academic Advising. www.nacada.ksu.edu/Sommissions/C14/index.htm (accessed on 31 August 2010).

boyd, d and Ellison, N. (2008). Social Network Sites: Definition, History, and Scholarship. Journal of

Computer-Mediated Communication, 13, 210-230.

Clark, L. and Roberts, S. Employer's Use of Social Networking Sites: A Socially Irresponsible Practice. Journal of Business Ethics, 95, 507-525.

De, K. (2009). 20 Social Media Best Practice Tips. www.krishnade.com/blog/2009/social-mediabestpractice/ (accessed on 28 June 2010).

ENGAGEMENTdb.com. (2009). The world's most valuable brands: Who's most engaged?

http://www.engagementdb.com/downloads.ENGAGEMENTdb Report 2009.pdf (accessed on 18 June 2010).

Esposito, A. (2007). Saving Face(book): Engage through Facebook and retain relevance. Academic Advising Today.

Ganim Barnes, N. and Mattson, E. (2010). Social Media and College Admissions: Higher-ed Beats Business in Adoption of New Tools for Third Year. UMass-Dartmouth Center for Marketing Research. www1.umass.edu/cmr/studiesresearch/socialmediaadmissions.pdf (accessed on 20 July 2010).

Lipka, S. (2009). Colleges “Don't Own the Conversation Anymore". Chronicle of Higher Education, 55(35), A4.

—. (2008). The Digital Limits of "In Loco Parentis". Chronicle of Higher Education, 54(26), A1. 
McDonald, F. (2009). Five Steps to Developing a Powerful Social Networking Strategy. University Business, 12(5), 43-46.

Mitrano, T. (2006). Thoughts on Facebook. Cornell Information Technologies, Cornell University. http://www.cit.cornell.edu.policies/socialnetworking/facebook.cfm (accessed on 5 August 2010).

McLuhan, M. (1964). Understanding Media. United Kingdom: Routledge \& Kegan Paul.

Odden, L. (2009). Best and Worst Practices Social Media Marketing.

http://www.toprankblog.com/2009/02/best-worst-practices-social-media-marketing/ (accessed on 18 June 2010).

-. (2008). Roadmap for Social Media Marketing Strategy.

http://www.toprankblog.com/2008/12/social-media/marketing/strategy-2/ (accessed on 26 July 2010).

Peluchette, J. and Karl, K. (2008). Social Networking Profiles: An Examination of Student Attitudes

Regarding Use and Appropriateness of Content. CyberPsychology \& Behavior, 11(1), 95-97.

Pou, J. (2010). How Academic Advisers Can Use Facebook to Apply Appreciative Advising. The Mentor:

An Academic Advising Journal, 12(1), www.psu.edu/dus/mentor/100310jp.htm.

Ray, B. (2007). Reaching the Masses: E-Newsletters and Facebook in Advising. The Mentor: An Academic Advising Journal, 9(3), www.psu.edu/dus/mentor/070830br.htm.

Sheridan, J. (2010). Social Media Best Practices: How to Create a Successful Program. Social Media404. www.usegraymatter.com/Downloads/SocMedia404 BestPractices.pdf (accessed on 28 July 2010).

Traxler, J. (2007). Advising Without Walls: An Introduction to Facebook as an Advising Tool. Academic Advising Today, 30(1), 9,13. 
University, Colorado State. (n.d.). Colorado State University Best Practices in Social Media.

http://www.socialmedia.colostate.edu/page/General-Best-Practices-in-Social-Media-.aspx (accessed on

5 July 2010). 